\title{
Study of 50 cases of modern management of ectopic pregnancy
}

\author{
Rajita S. Jani ${ }^{1}$, Devangi S. Munshi ${ }^{1}$, Shashwat K. Jani ${ }^{2}$, Sanjay P. Munshi ${ }^{2}$ \\ ${ }^{1}$ Department of Obstetrics \& Gynecology, L.G. Hospital, Maninagar, Ahmedabad, Gujarat, India \\ ${ }^{2}$ Department of Obstetrics \& Gynecology, V.S. General Hospital, Ellisbridge, Ahmedabad, Gujarat, India \\ Received: 23 March 2014 \\ Revised: 1 April 2014 \\ Accepted: 2 April 2014 \\ *Correspondence: \\ Dr. Rajita S. Jani, \\ E-mail: rajita.munshi@gmail.com \\ (C) 2014 Jani RS et al. This is an open-access article distributed under the terms of the Creative Commons Attribution \\ Non-Commercial License, which permits unrestricted non-commercial use, distribution, and reproduction in any \\ medium, provided the original work is properly cited.
}

\begin{abstract}
Background: In recent years, an increased incidence of ectopic gestation has been noted, which can be attributed to different reasons. Cases with ectopic gestation were studied and objectives were to study the incidence in various age groups, to study predisposing factors, to study different modes of clinical presentation, to study different sites of ectopic pregnancy and to study changing trends of modern management from radical surgical method to laparoscopic and medical management.

Methods: A study of 50 cases of tubal ectopic pregnancy was carried out from May 2009 to June 2011 in tertiary health centre. Patients managed with following treatment modalities were selected for study. (1) Medical management (MTX), (2) Laparoscopic management: salpingostomy, salpingectomy, (3) Laparotomy management: salpingostomy, segmental resection, fimbrial expression, salpingectomy.

Results: Lower abdominal pain was most common presenting symptom of ectopic pregnancy in $96 \%$ cases. The classical triad of symptoms (amenorrhea, abdominal pain and vaginal bleeding) was present in only $28 \%$ cases. PID contributed $24 \%$ cases and previous abortion contributed $28 \%$ cases indicating these two as the common risk factors. Ampulla was the commonest site for ectopic pregnancy, in 52\% cases. Salpingostomy performed mainly at this site. In $6 \%$ cases ectopic pregnancy in infundibulum were treated with fimbrial expression and fimbriectomy. $22 \%$ patients were managed medically (methotraxte). These were the cases having unruptured ectopic pregnancy and ectopic mass $<4 \mathrm{~cm}$. Laparoscopy was done in $34 \%$ cases, in 2 cases it was converted to laparotomy. While open laparotomy was done in $40 \%$ cases.

Conclusions: Ectopic pregnancy is a treatable problem. Ultrasonography plays central role in the diagnosis and management. Mode of therapy is determined by a combination of clinical symptoms, sonography findings and serum $\beta$-HCG values. Surgical management is still a cornerstone of management of ectopic pregnancy. But now scope of medical and laparoscopic management is also there. In recent years laparotomy has been replaced by laparoscopic surgery which is more conservative, minimally invasive and less time consuming which leads to quick recovery.
\end{abstract}

Keywords: Ectopic pregnancy, Laparoscopy

\section{INTRODUCTION}

\section{Ectopic gestation}

When fertilized ovum gets implanted at site other than normal position of uterine cavity it is known as ectopic gestation. Ectopic gestation is an unmitigated disaster of human production, and is the most important cause of maternal morbidity and mortality in $1^{\text {st }}$ trimester with major cause of reduced child bearing potential. $95-98 \%$ of all ectopic pregnancies are tubal.

\section{Increase incidence of ectopic gestation seen due to ${ }^{2}$}

$\rightarrow$ Dramatic rise in PID (6-10 fold) 
$\rightarrow$ Popularity of intrauterine devices (relative 7 times more in in situ IUCD)

\section{$\rightarrow \operatorname{ART}(5-7 \%)$}

\section{Decrease in rate of mortality}

The dramatic decrease in rate of mortality in patients of ectopic gestation can be directly attributable to earlier detection which allows us to pursue more conservative treatment modalities. High resolution USG and serum $\beta$ HCG level are helpful in early detection which allows the use of minimally invasive surgery or medical treatment which will significantly enhance both survival and conservation of reproductive capacity. ${ }^{3}$

The objectives of this study are:

- To study the incidence in various age groups.

- $\quad$ To study predisposing factors

- To study different modes of clinical presentation

- To study different sites of ectopic pregnancy

- To study changing trends of modern management from radical surgical method to laparoscopic and medical management

Course of ectopic pregnancy: ${ }^{4}$

- Spontaneous resolution

- Tubal abortion (Ampullary, fimbrial)

- Resolution

- Pelvic hematocele

- Hematosalpinx

- Tubal rupture (Isthmic, interstitial- at 12-16 wks)

- Rupture followed by secondary abdominal pregnancy.

\section{Diagnostic modalities for ectopic pregnancy}

\section{Serial B-HCG titre}

- $\quad 66 \%$ rise in B-HCG titre is seen at 2 days in normal intrauterine pregnancy (IUP).

- $\quad 15 \%$ of normal IUP has $<66 \%$ rise at $48 \mathrm{hrs}$.

- $\quad$ So $53 \%$ rise is now considered to be normal for an IUP (Barnhart).
- $\quad$ Discriminating zone $\rightarrow 1500 \mathrm{IU} / \mathrm{ml}^{\text {of }} \beta \mathrm{HCG}^{5}$

- $\quad$ At this level of $\beta H C G$, IUP must be located.

- $\quad$ However 1000 IU \& 2000 IU are also suggested.

- There is a decrease of $21-35 \%$ if spontaneous abortion occurs.

- $\quad$ Slower decrease or slower increase suggests ectopic pregnancy.

- In $17 \%$ patients with Ectopic Pregnancy $\beta \mathrm{HCG}$ doubling time is normal.

- $\quad$ Progesterone level ${ }^{5}$

○ It has a poor diagnostic value.

○ $>25 \mathrm{ng} / \mathrm{ml}$ suggests normal IUP.

$\circ \quad<5 \mathrm{ng} / \mathrm{ml}$ suggests abortion.

- Ectopic Pregnancy can have range from 5-25 ng.

- Limitations include patients undergoing infertility treatment via IVF.

\section{Features seen on TVS (Transvaginal ultrasound) ${ }^{5}$}

- $\quad$ Ectopic cardiac activity $\rightarrow$ Diagnosis is $100 \%$

- $\quad$ Ectopic gestational. Sac $\rightarrow$ strong evidence

- $\quad$ Ectopic mass \& fluid in POD $\rightarrow$ moderately strong evidence

\section{Colour Doppler ${ }^{5}$}

Ring of fire sign seen around a cold uterus is diagnostic of ectopic gestation on color Doppler ultrasound.

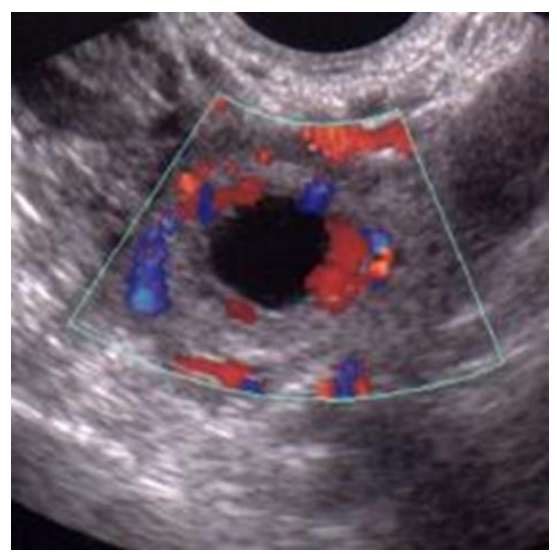

Figure 1: Color Doppler ultrasound. 


\section{Laparoscopy}

Laparoscopy is rarely required for diagnosis. Findings of laparoscopy may be normal in very early stages of ectopic pregnancy. The advantage is that a diagnostic scopy can be easily being converted to therapeutic scopy and treatment of ectopic gestation can be done simultaneously.

\section{Uterine curettage $e^{5}$}

Curettage is usually among the least used diagnostic modalities for ectopic pregnancy. It can help to differentiate from nonviable intrauterine pregnancy. The confirmatory finding for IUP is the presence of chorionic villi in normal saline.

\section{MRI}

For academic purposes, MRI scanning can be used to get an accurate diagnostic imaging for ectopic pregnancy. The MRI of choice is coronal section of T2-weighted fatsaturated MRI of the pelvis which clearly depicts the ectopic gestational sac with its exact location within the pelvic adnexa.

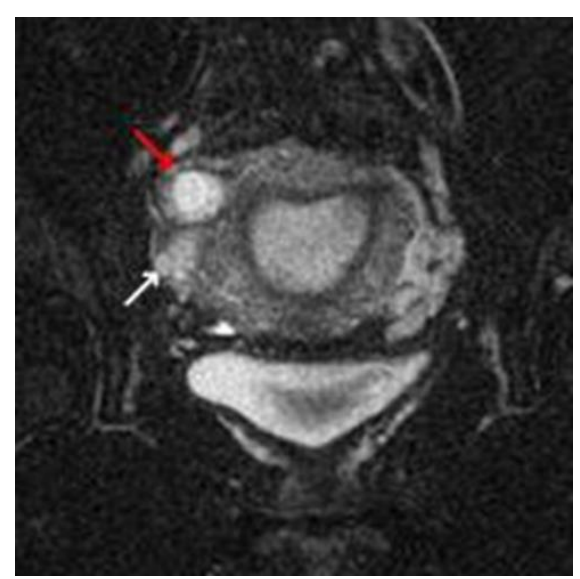

Figure 2: MRI of the pelvis.

\section{Medical management ${ }^{6}$}

\section{Selection criteria}

- $\quad$ Mass $<3.5 \mathrm{~cm}$

- $\quad \beta H C G<4000 \mathrm{mIU} / \mathrm{ml}$

- $\quad<6$ weeks gestational age

- Absent cardiac activity

- No hemoperitoneum

- Hemodynamically stable patient

- $\quad$ Patient must be compliant \& well counselled

\section{Methotrexate regimen}

- $\quad$ Single dose - $50 \mathrm{mg} / \mathrm{m}^{2} \mathrm{IM}$

- $\quad \beta H C G$ on day $4 \&$ day 7

- $\quad$ It should decrease by $15 \%$ of the initial level

- If it persists on day 7 , repeat the dose (max. 4 doses)

- If it decreases do weekly $\beta \mathrm{HCG}$ till Ectopic Pregnancy resolves $(<10 \mathrm{mIU})$

\section{METHODS}

A study of 50 cases of tubal ectopic pregnancy was carried out from May 2009 to June 2011 in tertiary health centre.

Patients managed with following treatment modalities were selected for study.

1) Medical management (MTX)

2) Laparoscopic management: Salpingostomy, Salpingectomy

3) Laparotomy management: Salpingostomy, segmental resection, fimbrial expression, salpingectomy

\section{RESULTS}

Figure 3 shows age distribution during study.

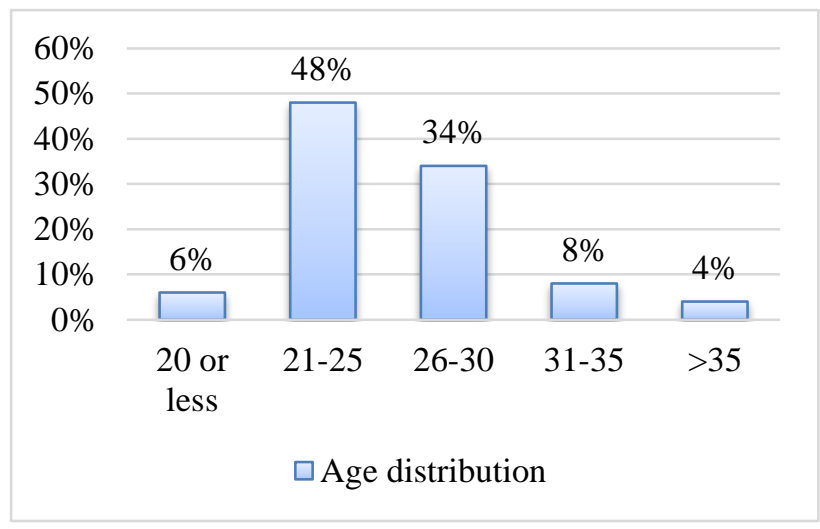

Figure 3: Age distribution.

Table 1: Parity distribution.

\begin{tabular}{|lll|}
\hline Parity & Number & Percentage \\
\hline 0 & 30 & $60 \%$ \\
\hline 1 & 11 & $22 \%$ \\
\hline 2 & 07 & $14 \%$ \\
\hline 3 & 01 & $02 \%$ \\
\hline 4 & 01 & $02 \%$ \\
\hline
\end{tabular}


As per study, $60 \%$ patients were nullipara and $82 \%$ were primipara or nullipara. This suggests that low parity has high chances of ectopic pregnancy.

Table 2: Symptoms.

\begin{tabular}{|llll|}
\hline Symptoms & Number & Percentage & $\begin{array}{l}\text { Gharono } \\
\text { et al. } \\
(\mathbf{2 0 0 2})\end{array}$ \\
\hline Lower abdominal pain & 48 & $96 \%$ & $83.6 \%$ \\
\hline Bleeding per vagina & 20 & $40 \%$ & $73 \%$ \\
\hline Amenorrhea & 44 & $88 \%$ & $77.6 \%$ \\
\hline Classical triad & 14 & $28 \%$ & - \\
\hline Syncope & 07 & $14 \%$ & $25.7 \%$ \\
\hline Nausea \& vomiting & 3 & $6 \%$ & $16.5 \%$ \\
\hline
\end{tabular}

Lower abdominal pain was most common presenting symptoms in $96 \%$ cases.

$88 \%$ cases had amenorrhea as the presenting symptom.

Classical triad of symptoms (amenorrhea, abdominal pain and vaginal bleeding) was present in only $28 \%$ cases.

Syncope was experienced by $14 \%$ patients, which was due to significant intraperitoneal hemorrhage.

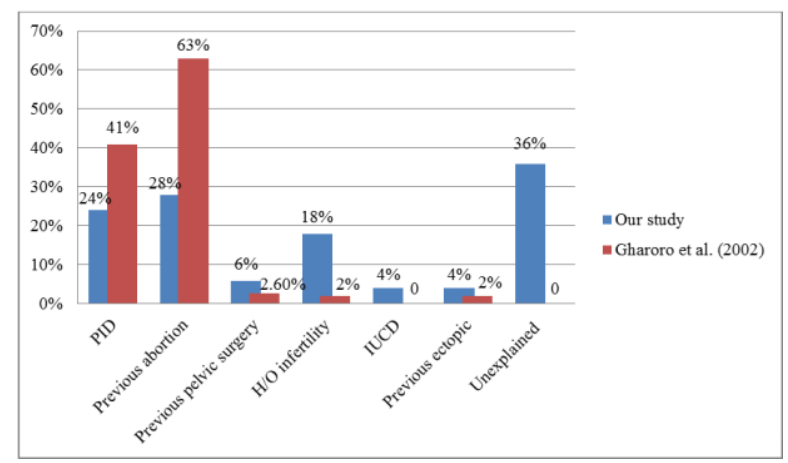

Figure 4: Risk factors.

PID contributed $24 \%$ cases and previous abortion contributed $28 \%$ cases indicating these two as the common risk factors.

Infertility was also a contributory factor in $18 \%$ cases.

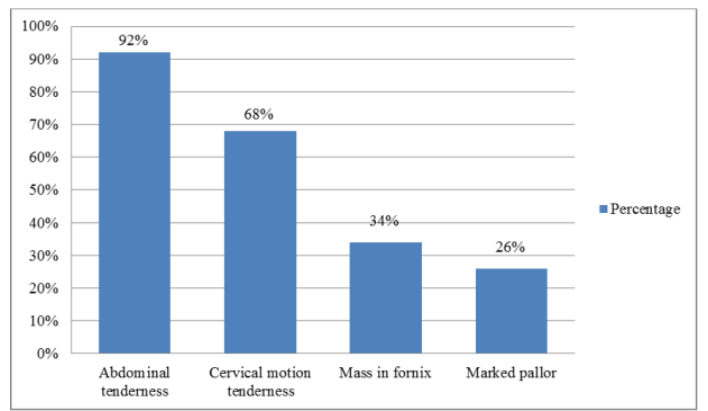

Figure 5: Presenting signs.
Abdominal tenderness was present in $92 \%$ cases and cervical motion tenderness was present in $68 \%$ cases.

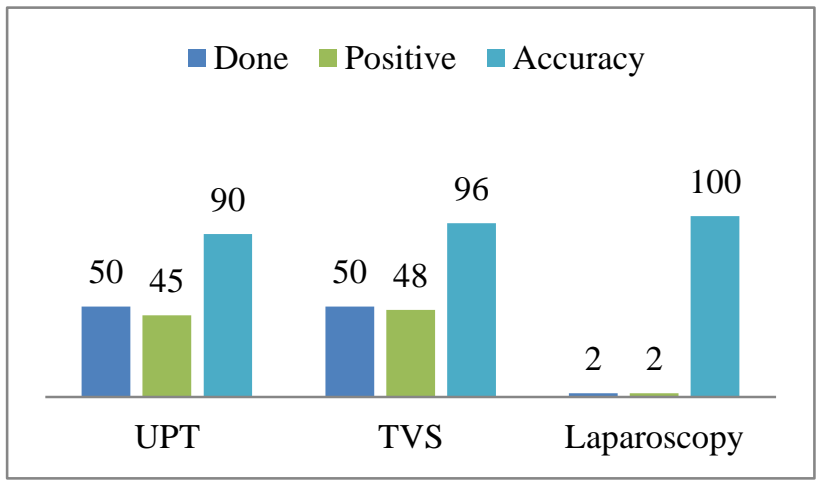

Figure 6: investigations done \& its accuracy.

UPT was done in all cases, positive in 45 cases.

$>$ TVS done in all cases, of which $96 \%$ cases showed positive results.

$>$ In 2 cases in which UPT \& TVS are negative, Laparoscopy done which shows $100 \%$ conclusive information.

Table 3: Mode of treatment.

\begin{tabular}{|llll|}
\hline Mode of treatment & Number & Percentage & $\begin{array}{l}\text { Caminiti } \\
\text { et al. } \\
(\mathbf{2 0 0 6 )}\end{array}$ \\
\hline Medical treatment & 11 & $22 \%$ & $21 \%$ \\
\hline Laparoscopy & 17 & $34 \%$ & $26 \%$ \\
\hline Laparotomy & 20 & $40 \%$ & $28 \%$ \\
\hline $\begin{array}{l}\text { Laparoscopy }+ \\
\text { Laparotomy }\end{array}$ & 02 & $04 \%$ & $25 \%$ \\
\hline MTX >laparotomy & 02 & $04 \%$ & - \\
\hline
\end{tabular}

$22 \%$ patients were managed medically (methotraxte). These were the cases having unruptured ectopic pregnancy and ectopic mass $<4 \mathrm{~cm}$.

Laparoscopy was done in $34 \%$ cases, in 2 cases it was converted to laparotomy.

Laprotomy was done in $40 \%$ cases.

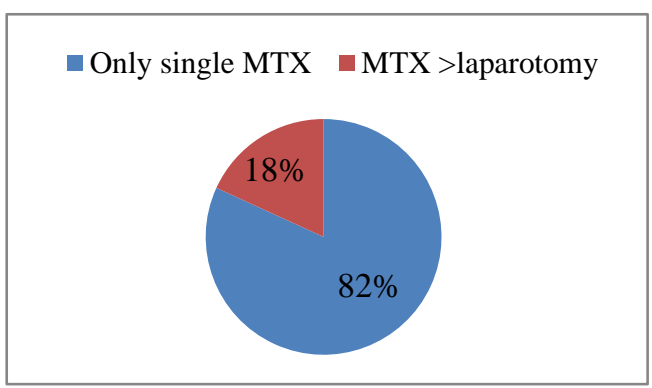

Figure 7: Success rate - Methotrexate (MTX). 
In $82 \%$ cases single dose Methotrexate was successful.

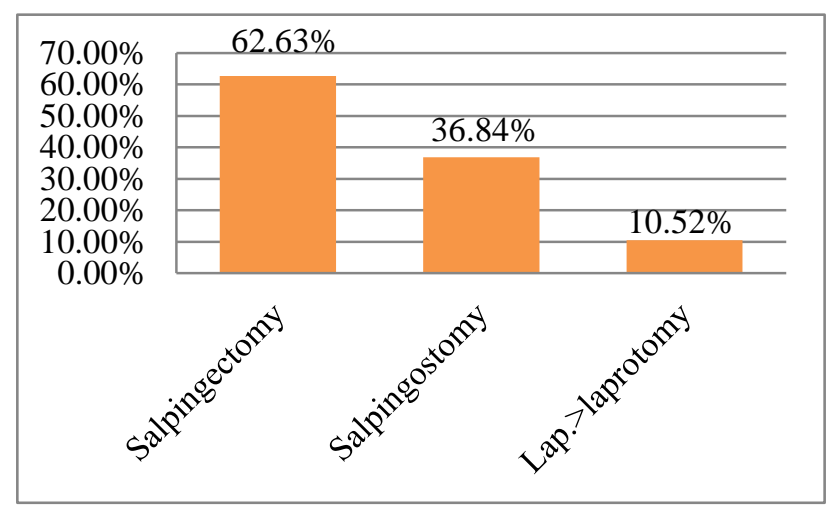

Figure 8: Type of surgery (laparoscopic).

Above chart suggests that in $63 \%$ cases salpingectomy was preferred. While in $36 \%$ cases salpingostomy was done.

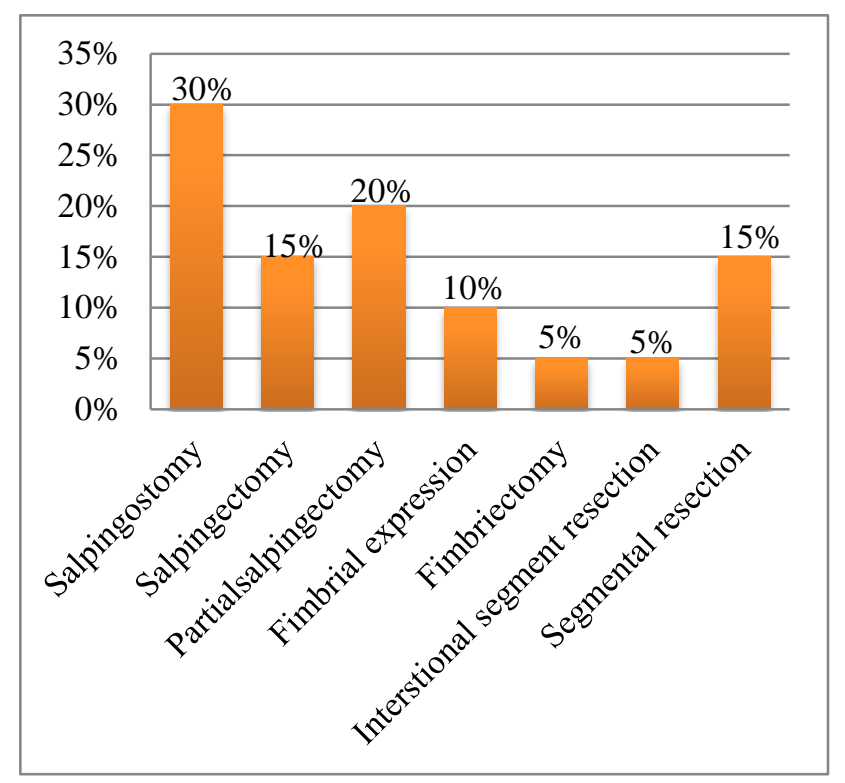

Figure 9: Type of laparotomy.

Above data shows that in laparotomy, 30\% patients had salpingostomy, while $20 \%$ patients underwent partial salpingectomy.

Table 4: Success rate of treatment.

\begin{tabular}{|ll|l|}
\hline Treatment & Success rate & Sraj et al. \\
\hline Methotrexate & $81.81 \%$ & $94.70 \%$ \\
\hline Laparoscopy & $89.40 \%$ & $91.40 \%$ \\
\hline Laparotomy & $100 \%$ & - \\
\hline
\end{tabular}

$>$ Success rate $81.81 \%$ for medical management by methotrexate

$>$ Laparoscopic management has a success rate of $89.4 \%$.

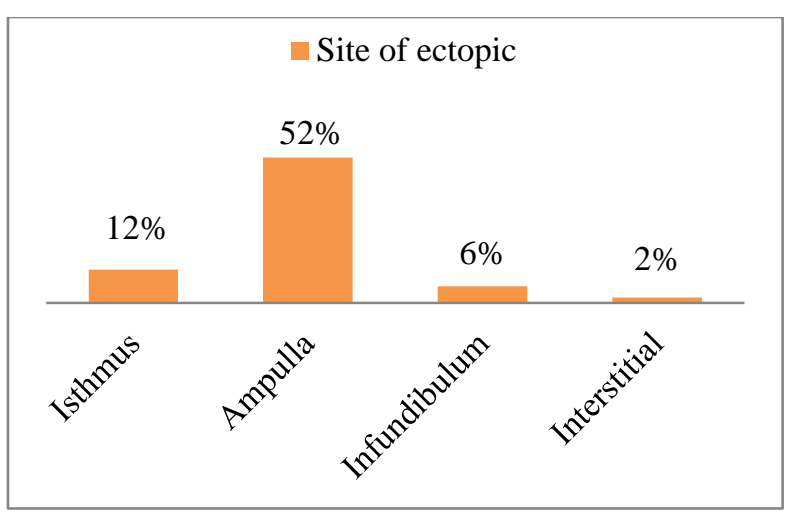

Figure 10: Site of ectopic pregnancy.

Ampulla was the commonest site for ectopic pregnancy, in $52 \%$ cases. Salpingostomy performed mainly at this site.

In $6 \%$ cases ectopic pregnancy in infundibulum were treated with fimbrial expression and fimbriectomy.

Table 5: Laparotomy vs. laparoscopy.

\begin{tabular}{|lll|}
\hline Complication & Laparotomy & Laparoscopy \\
\hline Morbidity & More & Less \\
\hline Postoperative adhesions & More & Less \\
\hline Risk of future ectopic & More & Less! \\
\hline Future fertility & Same & Same \\
\hline Persistent ectopic & Less! & More \\
\hline Experience / instruments & Routine & Special \\
\hline
\end{tabular}

Cochrane database review 2007

\section{Salpingectomy vs. Salpingostomy?}

Salpingectomy partial or total is only indicated when there is uncontrollable bleeding or future childbearing is not desired.

$>$ Risk of recurrent ectopic \& infertility are same.

$>$ Persistent trophoblastic activity is slightly more in salpingostomy.

\section{DISCUSSION}

Ectopic pregnancy is a treatable problem. Ultrasonography plays central role in the diagnosis and management.

Mode of therapy is determined by a combination of clinical symptoms, ultrasound findings and serum $\beta-\mathrm{HCG}$ values.

Surgical management is still a cornerstone of management of ectopic pregnancy, but now scope of medical and laparoscopic management is also there. 
In recent years laparotomy has been replaced by laparoscopic surgery which is more conservative, minimally invasive and less time consuming which leads to quick recovery.

Funding: No funding sources Conflict of interest: None declared

Ethical approval: Not required

\section{REFERENCES}

1. Surette AM, Dunham SM. Early pregnancy risks. In: AH DeCherney et al., eds. Current Diagnosis and Treatment Obstetrics \& Gynecology. 11th ed. New York: McGraw-Hill; 2013: 234-249.

2. Varma R, Gupta J. Tubal ectopic pregnancy. BMJ Clin Evid (Online). 2009;2009:1406.

3. Cunningham FG et al. Ectopic pregnancy. In: Cunningham FG et al., eds. Williams Obstetrics. 23rd ed. New York, NY: McGraw-Hill; 2010: 238256.

4. Leven ED et al. Ectopic pregnancy and spontaneous abortion. In: RG Nabel, eds. ACP Medicine. Hamilton, ON: BC Decker; 2010: Section 16, Chap. 6.

5. Fritz MA. Ectopic pregnancy. In: Fritz MA, Speroff L, eds. Clinical Gynecologic Endocrinology and Infertility. 8th ed. Philadelphia, PA: Lippincott Williams and Wilkins; 2011: 1383-1412.

6. American College of Obstetricians and Gynecologists (2008, reaffirmed 2012). Medical management of ectopic pregnancy. ACOG Practice Bulletin No. 94. Obstet and Gynecol. 2012;111(6):1479-85.

DOI: $10.5455 / 2320-1770 . i j \operatorname{cog} 20140618$

Cite this article as: Jani RS, Munshi DS, Jani SK, Munshi SP. Study of 50 cases of modern management of ectopic pregnancy. Int J Reprod Contracept Obstet Gynecol 2014;3:374-9. 